\title{
Human response to vibration in residential environments
}

\author{
David C. Waddington, ${ }^{\text {a) }}$ James Woodcock, and Eulalia Peris \\ Acoustics Research Centre, University of Salford, Salford, Greater Manchester, M5 4WT, United Kingdom \\ Jenna Condie \\ Salford Housing and Urban Studies Unit, Joule House, University of Salford, Greater Manchester, \\ M5 4WT, United Kingdom
}

\author{
Gennaro Sica and Andrew T. Moorhouse \\ Acoustics Research Centre, University of Salford, Salford, Greater Manchester, M5 4WT, United Kingdom
}

Andy Steele

Salford Housing and Urban Studies Unit, Joule House, University of Salford, Greater Manchester, M5 4WT, United Kingdom

(Received 12 April 2013; revised 12 November 2013; accepted 15 November 2013)

\begin{abstract}
This paper presents the main findings of a field survey conducted in the United Kingdom into the human response to vibration in residential environments. The main aim of this study was to derive exposureresponse relationships for annoyance due to vibration from environmental sources. The sources of vibration considered in this paper are railway and construction activity. Annoyance data were collected using questionnaires conducted face-to-face with residents in their own homes. Questionnaires were completed with residents exposed to railway induced vibration $(\mathrm{N}=931)$ and vibration from the construction of a light rail system $(\mathrm{N}=350)$. Measurements of vibration were conducted at internal and external positions from which estimates of 24-h vibration exposure were derived for 1073 of the case studies. Sixty different vibration exposure descriptors along with 6 different frequency weightings were assessed as potential predictors of annoyance. Of the exposure descriptors considered, none were found to be a better predictor of annoyance than any other. However, use of relevant frequency weightings was found to improve correlation between vibration exposure and annoyance. A unified exposure-response relationship could not be derived due to differences in response to the two sources so separate relationships are presented for each source. (C) 2014 Acoustical Society of America. [http://dx.doi.org/10.1121/1.4836496]
\end{abstract}

PACS number(s): 43.40.Ng, 43.50.Qp, 43.50.Sr [LMW]

Pages: 182-193

\section{INTRODUCTION}

Exposure-response relationships are a vital tool for planners and policy makers to assess the potential impact of an environmental stressor on a population. Decades of research into the human response to transportation noise in residential environments have led to internationally accepted exposureresponse relationships (see, for example, Miedema and Oudshoorn, 2001; Miedema and Vos, 1998; Schultz, 1978) which have formed the basis of European Union and North American policy. As is the case with exposure to environmental noise, exposure to whole body vibration can result in adverse effects such as annoyance (Guski, 1999; Klæboe et al., 2003b; Woodroof and Griffin, 1987) and sleep disturbance (Arnberg et al., 1990; Ogren and Öhrström, 2009). However, primarily due to a shortage of relevant field data, few exposure-response relationships have been established for the human response to vibration in residential environments. This paper presents the main findings of a field survey conducted in the United Kingdom (UK) into the human response to vibration in residential environments. The main aim of this study was to derive exposure-response

\footnotetext{
a) Author to whom correspondence should be addressed. Electronic mail: d.c.waddington@salford.ac.uk
}

relationships for annoyance due to vibration from railway and construction sources.

There is a relatively large body of literature detailing laboratory studies into the human response to vibration. These studies have generally focused on perception thresholds (e.g., Parsons and Griffin, 1988), equal comfort contours (e.g., Morioka and Griffin, 2006), subjective magnitude (e.g., Howarth and Griffin, 1988), and just noticeable differences in magnitude and frequency (e.g., Bellmann, 2002), and the results from a number of these laboratory studies have informed the development of a number of national and international standards. Although providing valuable insight into psychophysical aspects of the human perception of vibration, there is little evidence of whether these laboratory results are generalizable to the human response to vibration under field conditions. A limited number of field studies into the human response to vibration in residential environments have been conducted. In a field survey conducted by Woodruff and Griffin (1987), 459 residents living in close proximity to railway lines in Scotland completed a questionnaire to determine perceptibility and annoyance due to railway induced vibration. Twenty-four hour measurements of vibration were conducted within 52 properties of residents who participated in the questionnaire. Annoyance was not found to be significantly correlated with any physical descriptor of vibration exposure but was found to be 
correlated with the number of train passes in a 24-h period. A socio-vibration study conducted in Norway (Klæboe et al., 2003a,b) succeeded in deriving exposure-response relationships for the human response to railway and road traffic induced vibration in residential environments. The response to vibration of 1503 residents was determined using questionnaires administered by a telephone interview and a semi-empirical model was employed to estimate internal vibration exposure for each of the residents. Exposureresponse relationships were modeled from these data using logistic and ordinal logit regression. In a field survey conducted in North America and Canada (Zapfe et al., 2009), questionnaires were conducted via telephone with 1306 respondents to determine annoyance due to railway induced vibration. Vibration exposure was estimated by external measurements which were used to develop attenuation curves. Exposure-response relationships were derived for exposure to both groundborne vibration and groundborne noise. The Swedish research project Train Vibration and Noise Effects (TVANE) studied the effects of railway vibration in residential environments and developed exposureresponse relationships showing an increase in annoyance with increasing vibration exposure quantified as vibration velocity (Gidlöf-Gunnarsson et al., 2012). Recently, concerning the effect of combined noise and vibration from railway sources, Schomer et al. (2012) suggested the need to develop separate predictions for annoyance due to railway noise for railway sources that produce perceptible vibrations and for those that do not.

A secondary effect of groundborne vibration is vibration induced rattle. Exposure to vibration induced rattle has been shown to significantly influence the annoyance response to noise. A study by Schomer and Neathammer (1987) suggested that the presence of rattle induced by military helicopters caused an offset of $12 \mathrm{~dB}$ in the annoyance response to noise by a factor when there was "little vibration or rattles" and $20 \mathrm{~dB}$ when there were "high levels of vibration and rattles." Two related field studies (Fidell et al., 1999, 2002) investigated the relationship between low-frequency aircraft noise and annoyance due to rattle and vibration. Although no concrete conclusions were drawn from this study, it was suggested that the relationship between annoyance due to vibration induced rattle and low frequency noise exposure could complement the interpretation of the exposure-response relationships for aircraft noise in situations with low flying aircraft or ground noise from aircraft with high levels of annoyance explained in part by vibration induced rattling of elements such as window frames and household objects such as crockery.

Between the various national and international standards providing guidance on the topic, there is currently no consensus as to the most appropriate single figure descriptor of vibration exposure with regards to human response. Common descriptors include energy averages such as rootmean-squared acceleration, cumulative descriptors such as the Vibration Dose Value (VDV), and maximum running root-mean-squared values. These descriptors are generally calculated from frequency weighted acceleration or velocity. Frequency weightings are designed to reflect the frequency dependence of vibration perception. Due to the differences between assessment methods, comparison of results between socio-vibration studies is problematic.

The overall aim of the project detailed in this paper was to determine whether exposure-response relationships exist for human vibration in residential environments, and if so, does this correlate with existing descriptors of vibration exposure or some other descriptor. This paper outlines the results of the main study:

(1) The measurement of vibration, i.e., the "exposure" part of the required exposure-response relationship;

(2) the social science developments of the project, i.e., the "response" part of the exposure-response relationship; and

(3) the analysis of the exposure response relationships and descriptors.

It does not address what the results may mean for future policy development on vibration.

This paper begins with an overview of the methodologies employed for the collection of vibration and social survey data. A general description of each of the measurement sites is presented. A brief summary is provided of the analysis techniques used to determine 24-h vibration exposure from the data collected through the field work. Finally, the work conducted to coordinate the exposure and response data is summarized.

\section{METHODS}

\section{A. Determination of response}

\section{Design of the questionnaire}

The objective of the social survey detailed in this paper was to provide a robust sample of measurements of the human response to vibration induced by railways and construction activities in residential environments. To realize this objective, a questionnaire was designed by researchers in the Salford Housing and Urban Studies Unit (Condie et al., 2011). In field studies into the community response to noise and vibration, response is generally measured in terms of annoyance with annoyance considered as a catchall concept for the negative evaluation of environmental conditions (Guski, 1999). Therefore, the primary response of interest that the questionnaire aimed to measure was self-reported annoyance. Additionally, as situational and attitudinal factors have been shown to influence the human response to noise (Fields and Walker, 1982; Fields, 1993; Miedema and Vos, 1999), the questionnaire also measured a variety of other factors such as self-reported sensitivity to vibration and noise, factors related to concern and fear of the source, and satisfaction with the home and neighborhood. The influence of these additional factors however is beyond the scope of this paper.

The questionnaire was based on a pilot questionnaire developed for Defra (TRL et al., 2007), the Nordtest method for the development of socio-vibration surveys (NT ACOU 106,2001 ), best practice guidelines for the measurement of annoyance due to noise set out by Team 6 of the International Commission on the Biological Effects of Noise (ICBEN) (Fields et al., 2001), and guidance from ISO/TS 15666:2003 
(2003). To avoid influencing response to questions on vibration and noise the social survey questionnaire was presented as a neighborhood satisfaction survey.

Following guidance from ICBEN (Fields et al., 2001) and ISO/TS 15666:2003 (2003), annoyance responses were measured on 5-point semantic and 11-point numerical scales.

\section{Distinguishing feeling vibration and hearing the effects of vibration}

To ensure consistency and comprehension when asking about vibration, any reference in the questionnaire to feeling vibration was always accompanied by the word "shaking." Similarly, any reference to hearing the effects of vibration was accompanied by the words "rattle, vibrate, or shake." These two different perceptual mechanisms were separated out in the questionnaire by asking respondents through which surfaces they have perceived vibration and which structures and objects they have heard or seen rattle, vibrate, or shake. However, when asking respondents how bothered, annoyed, or disturbed they are by vibration, these two perceptual mechanisms are assessed simultaneously in a single question as a measure of overall annoyance.

\section{Site identification, sampling, and implementation of questionnaire}

It is suggested in the Norwegian guidance document NT ACOU 106 that the primary objective in the selection of sites in socio-vibrational surveys is to achieve a sample of respondents exposed to a wide range of vibration magnitudes. Considering this, potential survey sites with a sufficient number of properties at a range of distances from the vibration source of interest were first identified using online mapping services. For each identified site, a site reconnaissance was conducted to assess its suitability. Through the reconnaissance it was ensured that there were no potentially perceptible sources of vibration other than the source of interest. For the railway source of vibration, questionnaires were conducted in 12 survey areas, each of which consisted of numerous sites, which spanned around $170 \mathrm{~km}$ along the length of the West Coast Mainline Railway in the UK, one of the busiest mixed usage lines in Europe. For the construction sources of vibration, questionnaires were conducted at sites along two extensions of a light rail system in a large city in the UK.

The questionnaires were conducted face-to-face with residents in their own home and took around $30 \mathrm{~min}$ to complete. Contact with residents was achieved via cold calling and a success rate of residents for which contact was made agreeing to take part in a questionnaire of $41 \%$ was achieved. This resulted in 931 completed questionnaires for residents living close to a railway and 350 completed questionnaires for residents living close to a construction source.

\section{B. Determination of exposure}

\section{General approach}

For the assessment of the vibration exposure with respect to human response in residential environments
ISO 2631-1:1997 (1997), BS 6472-1:2008 (2008), and the ANC guidelines (ANC, 2001) recommend that vibration is measured for a period of 24-h in the center of the floor of the room at which the magnitude of vibration is perceived to be greatest. As 1281 estimations of 24-h vibration exposure were required, this approach was not practicable. As a consequence, an alternative measurement approach was developed which encompassed elements of measurement and prediction. This measurement methodology was implemented using seismic force feedback accelerometers. The clocks between stand-alone units were synchronized using an inbuilt global positioning system.

\section{Estimation of vibration exposure from railway sources}

For the measurement of vibration from railway sources, long term vibration monitoring was conducted at external positions (labeled "Control Position" in Fig. 1) for a period of at least 24-h. During the long term monitoring, short term "snapshot" measurements, which were synchronized with the long term measurement, were conducted within the properties of residents who had completed a questionnaire. The short term measurements were generally around $30 \mathrm{~min}$ in duration, or a period that encompassed 5 to 10 train passes. For the internal snapshot measurements, the measurement position was taken as close to the center of the floor as possible of the room in which the respondent of the questionnaire stated that they could feel the strongest magnitude of vibration. The transmissibility between the two measurement positions was used to estimate 24-h vibration exposure within the respondent's property.

In cases where a snapshot measurement of internal vibration was either not conducted or unavailable due to data corruption, the internal vibration exposure was used from a similar type of property that was in the same measurement area and a similar distance from the vibration source. Using these methods, it was possible to estimate 24-h internal vibration exposure in 752 of the 931 properties in which a resident had taken part in a social survey questionnaire; 497 of these estimations were based on the transmissibility method and 255 were based on estimations of internal vibration in a similar property type.

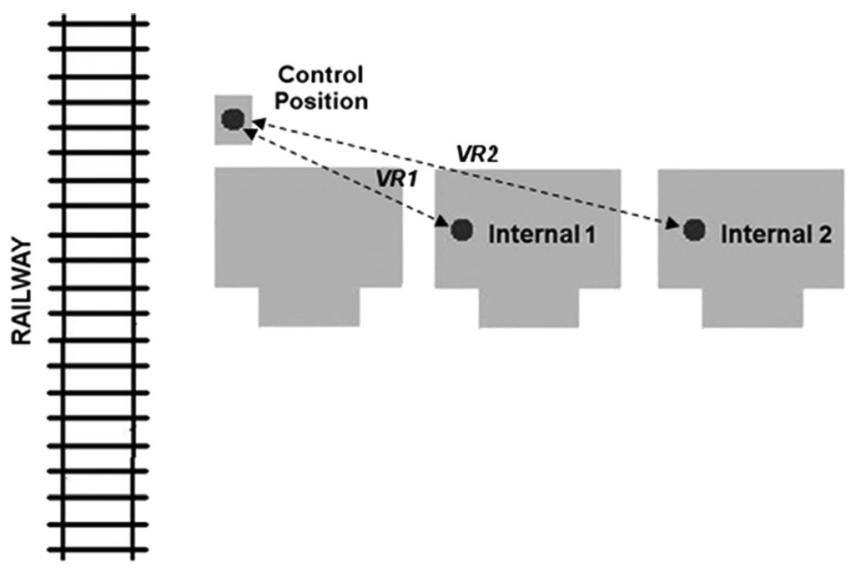

FIG. 1. Schematic of measurement approach for railway sources. 


\section{Estimation of vibration exposure from construction sources}

The measurement approach adopted for railway sources was found to be impracticable for the measurement of vibration induced by construction activity. Therefore, the measurement approach for construction vibration required more emphasis on extrapolation and correction of measured levels from one location to estimate exposure in other locations (Sica et al., 2013). Long term monitoring was conducted over a period of around 2 months to monitor the entire lifecycle of the construction activity (labeled Control Position in Fig. 2). At times of high activity (during piling operations, for example), a linear array of external measurements was conducted to determine attenuation laws for each measurement site. From the data collected via this method, semiempirical relationships for ground attenuation were derived for each measurement site and different vibration exposure metrics using the following equation which is based on the Bornitz equation (Woods, 1997):

$$
M(d)=M_{0} \sqrt{\frac{d_{0}}{d}} e^{-\alpha\left(d-d_{0}\right)},
$$

where $M$ is the magnitude of the vibration exposure metric to be predicted at distance $d, M_{0}$ is the measured magnitude of vibration exposure metric at distance $d_{0}$, and $\alpha$ is the material damping parameter to be estimated.

The value of $\alpha$ is estimated by regressing the measured parameters of interest against distance. Estimates of $\alpha$ were determined for each measurement site and the estimated ground attenuation relationships were then used to propagate the vibration exposure measured at the long term measurement position to the distance of the respondent's properties from the vibration source. By way of validation, the internal vibration exposure was measured directly inside a property $35 \mathrm{~m}$ from the construction source. The vibration exposure in this property was then predicted using the estimated ground attenuation relationships. The measured $W_{m}$ weighted root-mean-square (rms) acceleration inside the property was found to be $0.013 \mathrm{~m} / \mathrm{s}^{2}$; the predicted $W_{m}$ weighted rms acceleration inside the property was $0.019 \mathrm{~m} / \mathrm{s}^{2}$. The difference in the measured and predicted values represents a relative error of $3.3 \mathrm{~dB}$. Using these

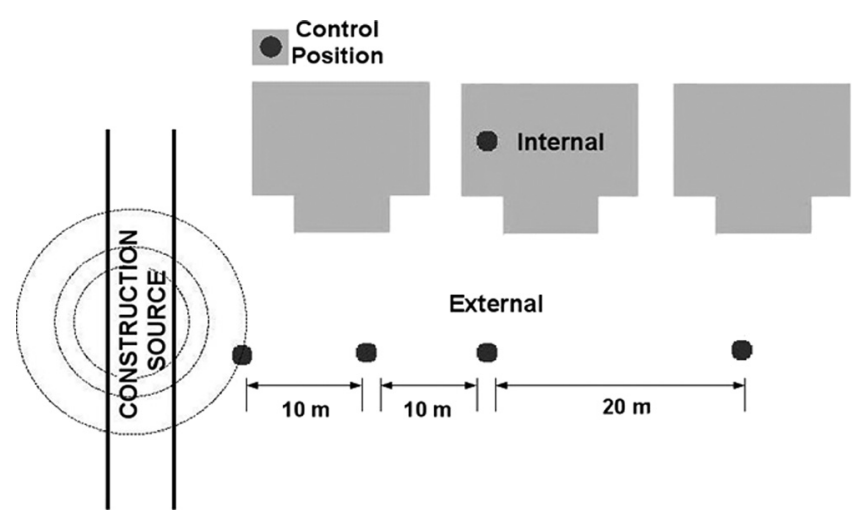

FIG. 2. Schematic of measurement approach for construction sources. methods, vibration exposure was estimated for 321 of the 350 respondents who had taken part in the social survey questionnaire.

\section{RESULTS}

\section{A. Description of the social survey sample}

\section{Characteristics of the railway sample}

Social survey questionnaires were conducted with 931 residents living near railways. In terms of demographic profile $44.2 \%$ of the respondents were male and $54.8 \%$ were female ( $1 \%$ missing values). Of this sample, $9.5 \%$ were aged $17-24,25.4 \%$ were $25-39,18.2 \%$ were $40-49,14.7 \%$ were $50-59,23.0 \%$ were $60-74,7.2 \%$ were $75-85$, and $1.6 \%$ were over 85 ( $0.3 \%$ missing values).

At the time of the survey $43.7 \%$ of the respondents were in employment, $6.3 \%$ were self-employed, $5.2 \%$ were students, $28.4 \%$ were retired, $6.4 \%$ were unemployed, $8.0 \%$ were carers or homemakers, and $0.3 \%$ were volunteers (1.7\% missing values).

In terms of property type, $48.7 \%$ of the respondents lived in a semi-detached property, $30.1 \%$ in a terraced property, $1.4 \%$ in an apartment, and $0.8 \%$ in a maisonette. Concerning tenure, $74.9 \%$ of respondents owned their homes, $3.6 \%$ part-owned their homes, $10.6 \%$ were in social housing, and $9.8 \%$ rented their property from a private landlord (1.2\% missing values).

Regarding the type of area, $0.2 \%$ of the respondents lived in the center of a large city, $32.7 \%$ in the suburbs/outskirts of a large city, $28.4 \%$ in a large town/small city, $37.8 \%$ in a small town, $0.4 \%$ in a village, and $0.3 \%$ in the countryside $(0.1 \%$ missing values). Concerning the use of the area, $79.2 \%$ of respondents lived in a mostly residential area or housing estate, $16.0 \%$ as mostly residential/commercial, $2.9 \%$ as mixed residential/industrial, and $1.8 \%$ as mixed residential/countryside ( $0.1 \%$ missing values).

Regarding the distance of dwellings from the source, $0.3 \%$ of the respondents lived between 5 and $15 \mathrm{~m}$ from the center of the railway, $9.4 \%$ between 15 and $25 \mathrm{~m}, 28.1 \%$ between 25 and $35 \mathrm{~m}, 25.8 \%$ between 35 and $45 \mathrm{~m}, 17.4 \%$ between 45 and $55 \mathrm{~m}, 8.2 \%$ between 55 and $65 \mathrm{~m}, 4.9 \%$ between 65 and $75 \mathrm{~m}, 2.9 \%$ between 75 and $85 \mathrm{~m}, 0.8 \%$ between 85 and $95 \mathrm{~m}$, and $2.2 \%$ over $95 \mathrm{~m}$.

\section{Characteristics of the construction sample}

Social survey questionnaires were conducted with 350 residents living near a source of construction vibration. In terms of demographic profile $37.9 \%$ of the respondents were male and $61.5 \%$ were female $(0.6 \%$ missing values $)$. Of this sample, $9.4 \%$ of respondents were aged 17-24, $26.2 \%$ were $25-39,20.5 \%$ were $40-49,15.1 \%$ were $50-59,21.1 \%$ were $60-74,6.3 \%$ were $75-85$, and $1.1 \%$ were over $85(0.3 \%$ missing values).

At the time of the survey $38.2 \%$ of the respondents were in employment, $6.8 \%$ were self-employed, $3.1 \%$ were students, $25.6 \%$ were retired, $11.7 \%$ were unemployed, $10.3 \%$ were carers or homemakers, and $0.3 \%$ were volunteers (3.0\% missing values). 
In terms of property type, $55.0 \%$ of the respondents lived in a semi-detached property, $36.3 \%$ in a terraced property, $1.1 \%$ in an apartment, and $2.6 \%$ in a detached property (4.3\% missing values). Concerning tenure $65.0 \%$ of respondents owned their homes, $2.6 \%$ part-owned their homes, $15.1 \%$ were in social housing, and $1.4 \%$ rented their property from a private landlord ( $0.9 \%$ missing values).

Regarding the type of area, $73.2 \%$ of the respondents lived in the suburbs/outskirts of a large city, $21.7 \%$ in a large town/small city, and $0.9 \%$ in a small town $(4.3 \%$ missing values). Concerning the use of the area, $27.6 \%$ of respondents lived in a mostly residential area or housing estate, $59.5 \%$ as mostly residential/commercial, and $8.5 \%$ as mixed residential/industrial (4.3\% missing values).

Regarding the distance of dwellings from the source, $15.6 \%$ of the respondents lived between 5 and $15 \mathrm{~m}$ from the construction activity, $9.4 \%$ between 15 and $25 \mathrm{~m}, 11.8 \%$ between 25 and $35 \mathrm{~m}, 15.3 \%$ between 35 and $45 \mathrm{~m}, 12.4 \%$ between 45 and $55 \mathrm{~m}, 13.5 \%$ between 55 and $65 \mathrm{~m}, 6.8 \%$ between 65 and $75 \mathrm{~m}, 7.6 \%$ between 75 and $85 \mathrm{~m}, 2.1 \%$ between 85 and $95 \mathrm{~m}$, and $5.6 \%$ over $95 \mathrm{~m}$.

\section{B. Description of the measured vibration data}

Figures 3 and 4 show the distribution of estimated vibration exposures expressed in $W_{m}$ weighted rms acceleration for 752 of the residents who took part in a questionnaire for railway vibration and 321 of the residents who took part in a questionnaire for construction vibration, respectively. It can be seen from Figs. 3 and 4 that a wide range of vibration exposures were achieved for each of the vibration sources suggesting that the site selection methodology was successful.

\section{Vibration exposure descriptor}

\section{Types of descriptor}

There are three main types of a vibration exposure descriptor that are advocated in national and international standards for the assessment of human response: Energy equivalent rms type descriptors, maximum running rms values, and the VDV used in the UK. For energy equivalent

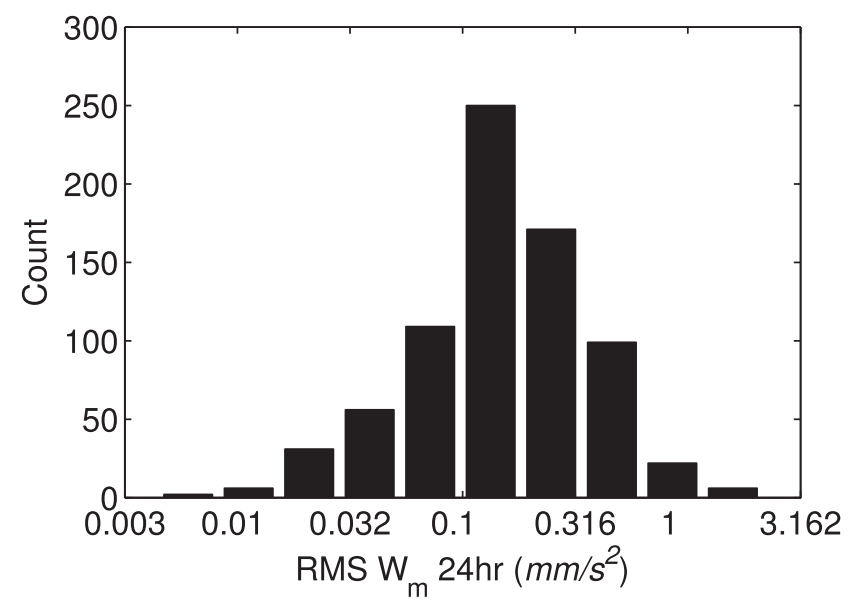

FIG. 3. Railway induced vibration exposure for 752 questionnaire respondents expressed in $W_{m}$ weighted rms acceleration.

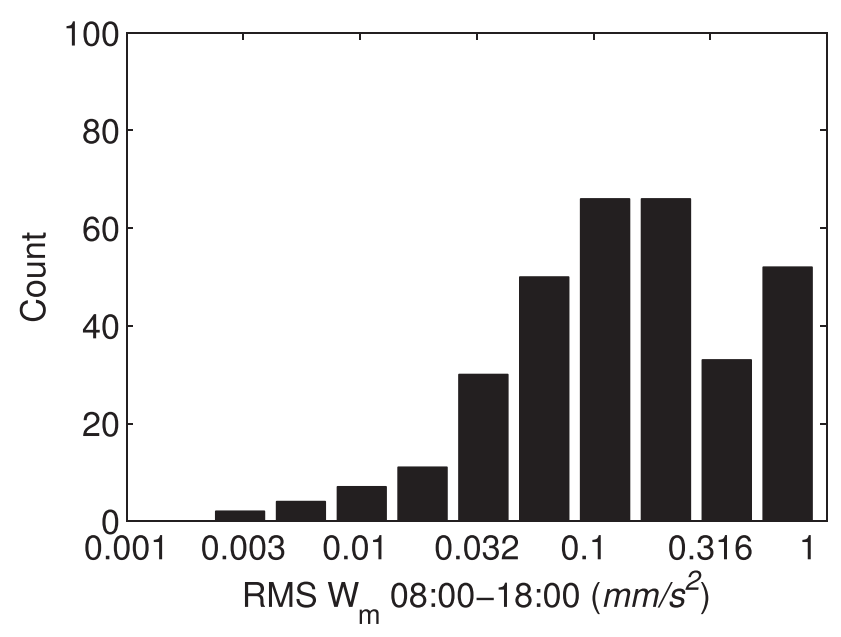

FIG. 4. Construction induced vibration exposure for 321 questionnaire respondents expressed in $W_{m}$ weighted rms acceleration.

type descriptors, the question also arises as to whether this descriptor is assessed only when vibration events are occurring or over the entire $24-\mathrm{h}$ evaluation period.

\section{Limitations to the descriptor analysis}

The analyses presented in this section were limited to the case studies for railway sources of vibration. As vibration exposure for the construction vibration dataset was based upon predictions derived from attenuation curves, any correlation between these predictions and human response will be dominated by the distance from the source rather than objective features of the vibration exposure. This suggests that the dataset of construction vibration is unsuitable for the evaluation of different vibration exposure descriptors.

\section{Descriptors considered}

A number of single figure descriptors of vibration exposure were calculated for the case studies in which estimations of internal acceleration time histories were derived. Table I provides a summary of the single figure descriptors calculated from the 497 estimates of 24-h internal vibration from railway activities. These descriptors were calculated for each case study based on the estimated internal vibration of all train events during a 24-h period. In addition to the descriptors presented in Table I, the 1st, 5 th, 10th, 50th, 90th, 95th, and 99th percentiles of the estimated 24-h internal acceleration time histories were also calculated.

\section{Most effective descriptor for prediction of annoyance}

To investigate the relationship between the different descriptors, a principal component analysis was carried out on a matrix of the calculated descriptors and it was found that more than $75 \%$ of the variance in the descriptor space is accounted for by the first principal component indicating that there is a high degree of correlation between the vibration exposure descriptors considered in this section. This finding can be verified by examining the correlation between 
TABLE I. Summary of vibration exposure descriptors considered. Where $\ddot{x}(n)$ is an acceleration time series, $N$ is the number of samples in the acceleration time series, and $T$ is the duration of the event in seconds.

\begin{tabular}{|c|c|c|}
\hline DESCRIPTOR & DESCRIPTOR TYPE & CALCULATION \\
\hline $\operatorname{RMS}\left(\mathrm{M} / \mathrm{S}^{2}\right)$ & ENERGY AVERAGE & $\ddot{x}_{\mathrm{rms}}=\sqrt{\frac{1}{N} \sum_{n=1}^{N} \ddot{x}(n)^{2}}$ \\
\hline ROOT MEAN QUAD (M/S²) & ENERGY AVERAGE & $\ddot{x}_{\mathrm{rmq}}=\sqrt[4]{\frac{1}{N} \sum_{n=1}^{N} \ddot{x}(n)^{4}}$ \\
\hline ROOT MEAN HEX (M/S²) & ENERGY AVERAGE & $\ddot{x}_{\mathrm{rmh}}=\sqrt[6]{\frac{1}{N} \sum_{n=1}^{N} \ddot{x}(n)^{6}}$ \\
\hline ROOT MEAN OCT $\left(\mathrm{M} / \mathrm{S}^{2}\right)$ & ENERGY AVERAGE & $\ddot{x}_{\mathrm{rmo}}=\sqrt[8]{\frac{1}{N} \sum_{n=1}^{N} \ddot{x}(n)^{8}}$ \\
\hline $\operatorname{VDV}\left(\mathrm{M} / \mathrm{S}^{1.75}\right)$ & CUMULATIVE DOSE & $\ddot{x}_{\mathrm{VDV}}=\sqrt[4]{\frac{T}{N} \sum_{n=1}^{N} \ddot{x}(n)^{4}}$ \\
\hline STANDARD DEVIATION & STATISTICAL & $\sigma=\sqrt{\frac{1}{N} \sum_{n=1}^{N}(\ddot{x}(n)-\bar{x})^{2}}$ \\
\hline SKEWNESS & STATISTICAL & $S_{k}=\frac{1}{N \cdot \sigma^{3}} \sum_{n=1}^{N}(\ddot{x}(n)-\bar{x})^{3}$ \\
\hline KURTOSIS & STATISTICAL & $K_{t}=\frac{1}{N \cdot \sigma^{4}} \sum_{n=1}^{N}(\ddot{x}(n)-\bar{x})^{4}$ \\
\hline PEAK PARTICLE ACCELERATION (M/S²) & MAXIMUM & MAXIMUM DEVIATION OF THE TIME SERIES FROM THE MEAN \\
\hline$L_{\mathrm{MAX}}\left(\mathrm{DB} \mathrm{RE} 1 \times 10^{-6} \mathrm{M} / \mathrm{S}^{2}\right)$ & RUNNING RMS & MAXIMUM $1 \mathrm{~S}$ RUNNING AVERAGE RMS OVER AN EVENT \\
\hline$L_{\mathrm{EQ}}\left(\mathrm{DB} \mathrm{RE} 1 \times 10^{-6} \mathrm{M} / \mathrm{S}^{2}\right)$ & ENERGY AVERAGE & $L_{\mathrm{eq}}=20 \log _{10}\left(\frac{\ddot{x}_{\mathrm{rms}}}{1 \times 10^{-6}}\right)$ \\
\hline$L_{E}\left(\mathrm{DB} \mathrm{RE} 1 \times 10^{-6} \mathrm{M} / \mathrm{S}^{2}\right)$ & ENERGY AVERAGE & $L_{E}=20 \log _{10}\left(\frac{\ddot{x}_{\mathrm{rms}}}{1 \times 10^{-6}}\right)+10 \log _{10}(T)$ \\
\hline
\end{tabular}

the different vibration exposure descriptors and self-reported annoyance measured in the social survey questionnaire. These correlations were assessed using Spearman's rank correlation coefficient on both the 5-point semantic and 11-point numerical annoyance response scales. It can be seen from Table II that, excluding skewness and kurtosis, each of the vibration exposure descriptors considered exhibits a similar magnitude of correlation with self-reported annoyance. These results suggest that, for the dataset of railway induced vibration under analysis, the single figure descriptors considered in this section are equally effective predictors of annoyance. These results are consistent with the findings of Zapfe et al. (2009).

\section{Effectiveness of frequency weightings}

To investigate the effectiveness of the different frequency weightings recommended in different national and international standards, the Spearman's rank correlation coefficient was calculated between self-reported annoyance and vibration exposure expressed in terms of rms in the vertical and horizontal directions for acceleration, velocity, and using the appropriate frequency weightings defined in ISO 2631-2:2003 (2003), BS ISO 2631-1:1997 (1997), and BS 6472-1:2008 (2008). The frequency weightings were realized by means of digital infinite impulse response filters, the coefficients of which are defined in BS 6841:1987 (1987) and BS EN ISO 8041:2005 (2005).

\section{Horizontal and vertical weightings}

Table III presents the Spearman's rank correlation coefficients between annoyance ratings measured on the two response scales and rms vibration calculated using different

TABLE II. Spearman's correlation coefficient between different descriptors of 24-h vibration exposure and self-reported annoyance $(N=752)$. $* p<0.05, * * p<0.01$, - not significant.

\begin{tabular}{|c|c|c|}
\hline DESCRIPTOR & 5-POINT SCALE & 11-POINT SCALE \\
\hline $\operatorname{RMS}\left(\mathrm{M} / \mathrm{S}^{2}\right)$ & $0.08 *$ & $0.09 *$ \\
\hline ROOT MEAN QUAD (M/S²) & $0.09 *$ & $0.08 *$ \\
\hline ROOT MEAN HEX (M/S²) & $0.10 * *$ & $0.09 *$ \\
\hline ROOT MEAN OCT $\left(\mathrm{M} / \mathrm{S}^{2}\right)$ & $0.10 * *$ & $0.09 *$ \\
\hline $\operatorname{VDV}\left(\mathrm{M} / \mathrm{S}^{1.75}\right)$ & $0.10 * *$ & $0.10 * *$ \\
\hline STANDARD DEVIATION & $0.08 *$ & $0.09 *$ \\
\hline SKEWNESS & - & - \\
\hline KURTOSIS & - & - \\
\hline $\begin{array}{l}\text { PEAK PARTICLE } \\
\text { ACCELERATION }\left(\mathrm{M} / \mathrm{S}^{2}\right)\end{array}$ & $0.11 * *$ & $0.10 * *$ \\
\hline$L_{\mathrm{MAX}}\left(\mathrm{DB} \mathrm{RE} 1 \times 10^{-6} \mathrm{M} / \mathrm{S}^{2}\right)$ & $0.10 * *$ & $0.10 * *$ \\
\hline$L_{\mathrm{EQ}}\left(\mathrm{DB} \mathrm{RE} 1 \times 10^{-6} \mathrm{M} / \mathrm{S}^{2}\right)$ & $0.08 *$ & $0.11 * *$ \\
\hline $\operatorname{SEL}\left(\mathrm{DB} R E 1 \times 10^{-6} \mathrm{M} / \mathrm{S}^{2}\right)$ & $0.08 *$ & $0.12 * *$ \\
\hline
\end{tabular}


TABLE III. Spearman's correlation coefficient between frequency weighted rms vibration exposure and self-reported annoyance $(N=752)$. $* p<0.05$, $* * p<0.01, * * * p<0.001$.

\begin{tabular}{|c|c|c|}
\hline & $\begin{array}{l}\text { 5-POINT } \\
\text { SCALE }\end{array}$ & $\begin{array}{l}\text { 11-POINT } \\
\text { SCALE }\end{array}$ \\
\hline VERTICAL ACCELERATION $\left(\mathrm{M} / \mathrm{S}^{2}\right)$ & $0.08 *$ & $0.09 *$ \\
\hline $\begin{array}{l}\text { WEIGHTED VERTICAL } \\
\text { ACCELERATION }\left(W_{B}\right)\left(\mathrm{M} / \mathrm{S}^{2}\right)\end{array}$ & $0.12 * * *$ & $0.12 * * *$ \\
\hline $\begin{array}{l}\text { WEIGHTED VERTICAL } \\
\text { ACCELERATION }\left(W_{K}\right)\left(\mathrm{M} / \mathrm{S}^{2}\right)\end{array}$ & $0.13 * * *$ & $0.13 * * *$ \\
\hline $\begin{array}{l}\text { WEIGHTED VERTICAL } \\
\text { ACCELERATION }\left(W_{M}\right)\left(\mathrm{M} / \mathrm{S}^{2}\right)\end{array}$ & $0.12 * *$ & $0.13 * * *$ \\
\hline VERTICAL VELOCITY (M/S) & $0.13 * * *$ & $0.13 * * *$ \\
\hline $\begin{array}{l}\text { HORIZONTAL } \\
\text { ACCELERATION }\left(\mathrm{M} / \mathrm{S}^{2}\right)\end{array}$ & $0.08 *$ & $0.11 * *$ \\
\hline $\begin{array}{l}\text { WEIGHTED HORIZONTAL } \\
\text { ACCELERATION }\left(W_{D}\right)\left(\mathrm{M} / \mathrm{S}^{2}\right)\end{array}$ & $0.17 * * *$ & $0.18 * * *$ \\
\hline $\begin{array}{l}\text { WEIGHTED HORIZONTAL } \\
\text { ACCELERATION }\left(W_{M}\right)\left(\mathrm{M} / \mathrm{S}^{2}\right)\end{array}$ & $0.15 * * *$ & $0.16^{* * * *}$ \\
\hline HORIZONTAL VELOCITY (M/S) & $0.14 * * *$ & $0.16^{* * * *}$ \\
\hline
\end{tabular}

frequency weightings in the vertical and horizontal directions. It can be seen from Table III that a marginal improvement in the magnitude and significance of correlation can be observed when the appropriate frequency weightings are applied in both the vertical and horizontal directions of excitation. Similarly, expressing vibration exposure in terms of velocity results in a higher correlation than if the exposure is expressed in terms of unweighted acceleration; this result is expected as, for vibration in the vertical direction, the frequency weighting curves approximate velocity at frequencies above around $16 \mathrm{~Hz}$. It can also be noted that vibration exposure in the horizontal direction exhibits a slightly higher correlation with annoyance than vibration in the vertical direction.

\section{Vibration direction to be assessed}

There is some discrepancy between national and international standards regarding the direction of vibration to be assessed with regards to human response. BS 6472-1:2008 (2008) suggests that if the magnitude of vibration is clearly dominant in one axis, only the direction with the highest magnitude need be considered. ISO 2631-2:2003 (2003) on the other hand suggests that vibration exposure be expressed as a vector sum of the weighted rms acceleration measured in three orthogonal directions. In Fig. 5, 24-h VDVs in the vertical direction are compared with a vector sum of the VDVs calculated for the three measured directions. Figure 5 indicates that the vibration in the vertical direction dominates the dataset and that including the horizontal components has almost no influence on the estimated 24-h vibration exposure. Therefore, vibration exposure in the remainder of this paper will be considered only in the vertical direction.

\section{Statistical model}

The statistical model used to formulate the exposureresponse relationships presented in this paper is based

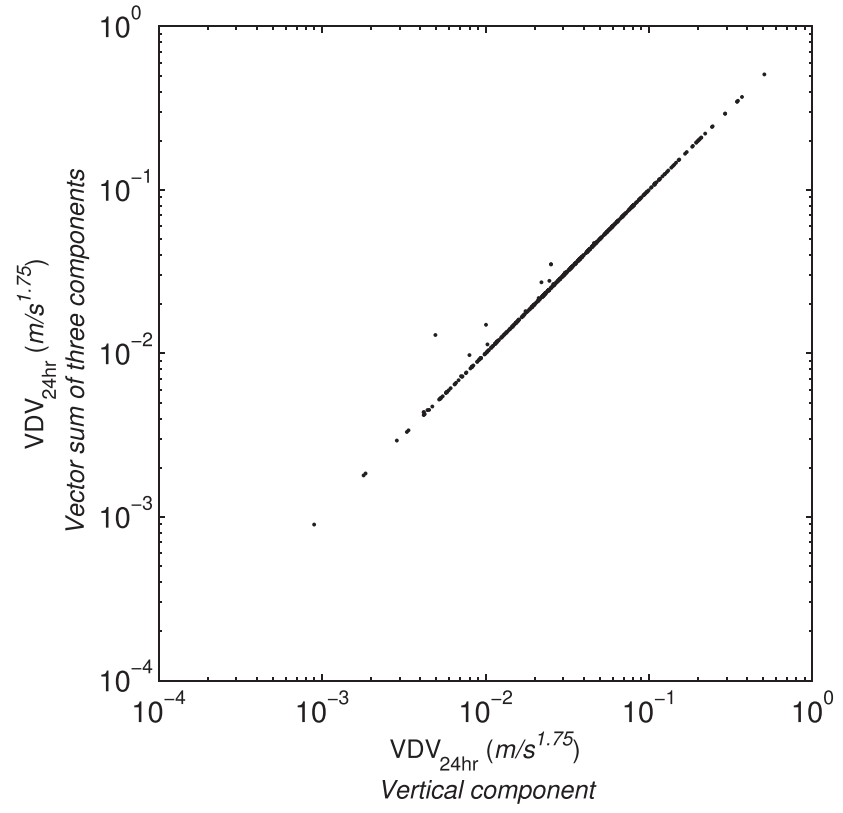

FIG. 5. Comparison of VDV of the vertical and combined components.

upon the model proposed by Groothuis-Oudshoorn and Miedema (2006). The relationships take the form of curves indicating the percentage of people expressing annoyance above a given threshold $(C)$ for a given vibration exposure $(X)$,

$$
p_{C}(X)=100 \times\left(1-\Phi\left[\frac{C-\mathbf{X} \boldsymbol{\beta}}{\sigma}\right]\right),
$$

where $\Phi$ is the cumulative normal distribution function, $\mathbf{X}$ is a vector of vibration exposures, $\boldsymbol{\beta}$ are model coefficients to be estimated, and $\sigma$ is the standard error. The coefficients of this model were estimated by maximum likelihood.

The annoyance thresholds $C$ reported will be $28 \%, 50 \%$, and $72 \%$ of the annoyance scale which will be referred to as "percent slightly annoyed" (\%SA), "percent annoyed" (\%A), and "percent highly annoyed" (\%HA), respectively. Respondents stating that they are unable to feel vibration have been recoded to the lowest category on the annoyance response scale.

The 95\% upper and lower confidence limits of this model at a given exposure level $x$ are given as

$$
C_{L U}=\mathbf{x}^{\mathbf{T}} \mathbf{b} \pm Z \sqrt{\left(\mathbf{x}^{\mathbf{T}} \Sigma_{b} \mathbf{x}\right)}
$$

where $\mathbf{x}^{\mathbf{T}}$ is the transpose of the vector $(1, x), \boldsymbol{\Sigma}_{b}$ is the covariance matrix of the $\boldsymbol{\beta}$ coefficients, and $\mathbf{b}$ is a vector of the estimates of the $\boldsymbol{\beta}$ coefficients. $Z=1.96$ for a standard normal distribution.

The confidence limits for $p_{C}(X)$ can then be expressed as

$$
1-\Phi\left(\frac{C-C_{L, U}}{\sigma}\right)
$$




\section{E. Functional form of exposure descriptor}

Models were tested with the exposure descriptor described in absolute units and logarithmic units. The likelihoods of the two models were evaluated and in all cases the descriptor expressed in logarithmic form was found to exhibit a significant improvement in the model fit. Considering the high degree of correlation between the different vibration exposure descriptors that were assessed, the relationships in the remainder of this paper will be expressed in terms of $W_{m}$ weighted rms and $W_{b}$ weighted VDV.

\section{F. Vibration perception}

In the social survey questionnaire, before respondents were asked about annoyance due to vibration they were first asked to indicate whether they were able to feel vibration from a variety of sources. The response to this question was of a binary outcome, either "Yes" or "No." A binary probit model was calculated with the response to this question as the dependent variable and vibration exposure expressed as $W_{b}$ weighted VDV as the independent variable. The resulting model is a curve that describes the proportion of respondents able to feel vibration for a given vibration exposure. Figure 6 shows the results of this model for vibration due to railway and construction activities. Figure 6 suggests that a similar proportion of respondents reported being able to feel vibration at a similar magnitude of VDV for both railway and construction sources. For railway induced vibration, $50 \%$ of the subjects reported being able to feel vibration at a VDV of $0.0082 \mathrm{~m} / \mathrm{s}^{1.75}$. For construction induced vibration, $50 \%$ of the subjects reported being able to feel vibration at a VDV of $0.0079 \mathrm{~m} / \mathrm{s}^{1.75}$. As the VDV describes a cumulative dose, it is not possible to compare these values to perception thresholds which are generally expressed as peak type descriptors or the rms of short vibration exposures. As the question of whether a stimulus is perceived or not will result in less intra-subject variability than measures of response such as annoyance, this result provides confidence that responses to the two different sources of vibration can be compared.

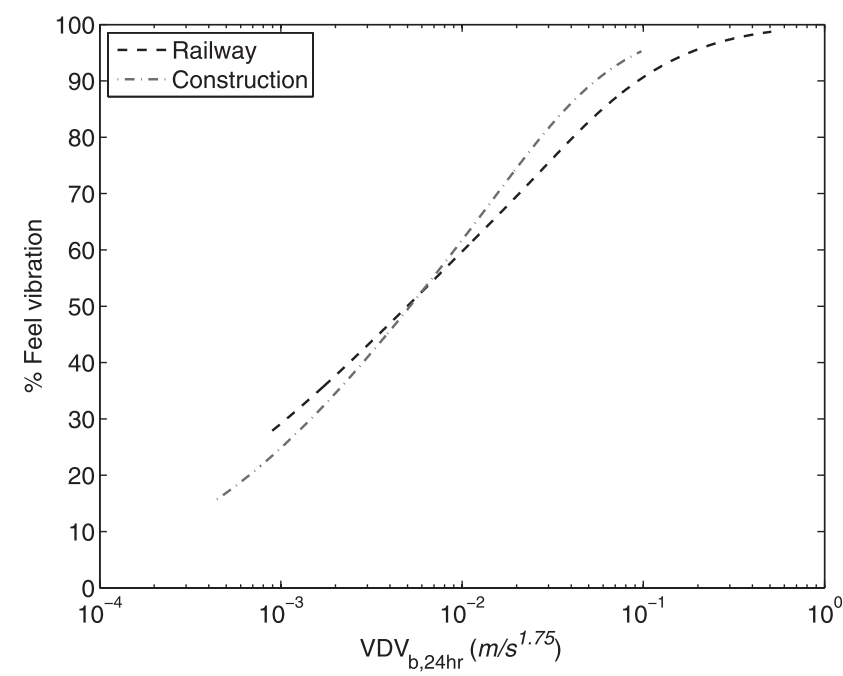

FIG. 6. Proportion of respondents reporting feeling vibration for a given vibration exposure from railway sources $(N=752)$ and construction sources $(N=321)$.

\section{G. Source specific exposure-response relationships}

\section{Railway}

Figures 7 and 8 show exposure-response relationships for railway induced vibration assessed according to $\mathrm{BS}$ 6472-1:2008 (2008) and ISO 2631-2:2003 (2003), respectively. In each case vibration exposure is assessed over a 24$\mathrm{h}$ evaluation period.

\section{Construction}

Figures 9 and 10 show exposure-response relationships for construction induced vibration assessed according to BS 6472-1:2008 (2008) and ISO 2631-2:2003 (2003), respectively. In each case vibration exposure is assessed over the period 8:00 to $18: 00$, the period over which the source was operational.

\section{H. Synthesis curve}

In previous studies, exposure-response relationships have been derived for mixed sources (Klæboe et al., 2003b), namely railway induced vibration and road traffic induced vibration. To investigate the influence of the vibration source type on self-reported annoyance due to vibration exposure, data from the railway and construction source types were pooled together and a dummy variable was created for source type. Exposure-response models were calculated with and without the source type dummy variable. The parameter estimate for the source dummy variable was found to be significant $(z=8.86, p<0.001)$ and a likelihood ratio test confirmed that a model with the source dummy variable was a significantly better fit than one without $\left[\chi^{2}(1)=83.2\right.$, $p<0.001]$. This result indicates that the exposure-response relationships for railway and construction sources cannot be combined and separate relationships are needed for the two different sources. This result can be confirmed by comparing Figs. 7 and 9 which show the exposure-response

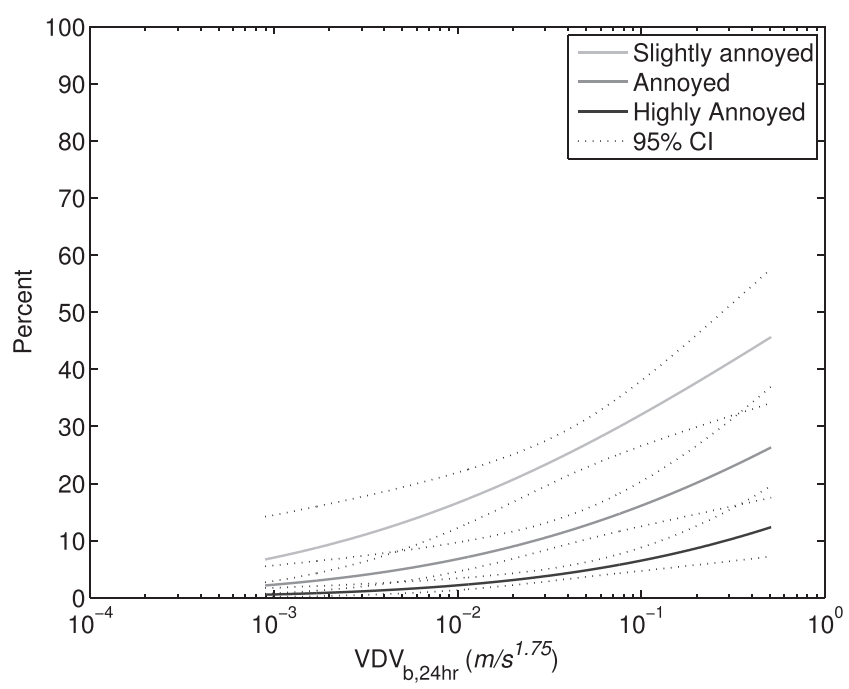

FIG. 7. Exposure-response relationship showing the proportion of people reporting different degrees of annoyance for a given vibration exposure from railway assessed according to BS 6472-1:2008 (2008). Curves are shown in their $95 \%$ confidence intervals. $\left(N=752, R_{\text {pseudo }}^{2}=0.01, p<0.001\right.$. $)$ 


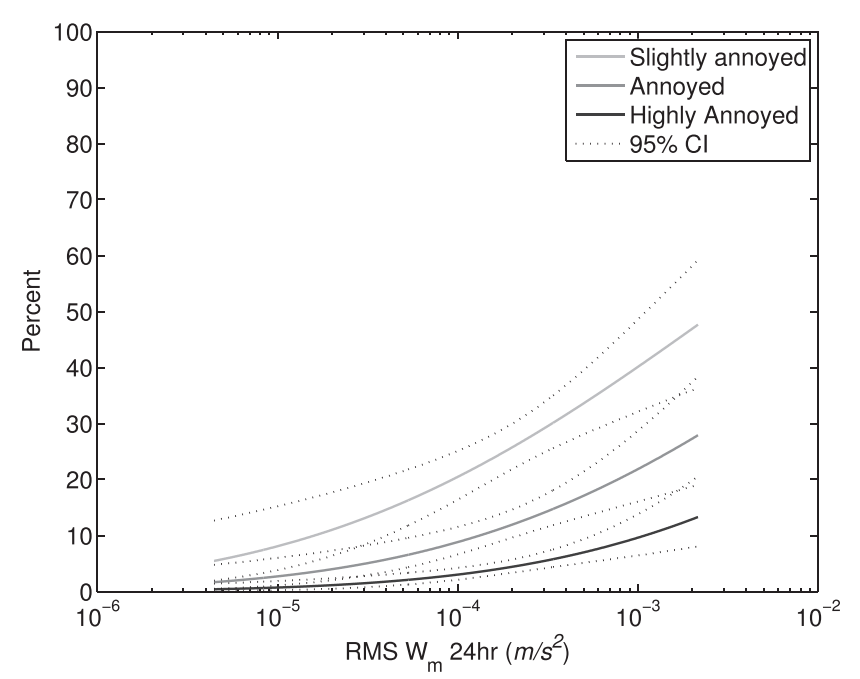

FIG. 8. Exposure-response relationship showing the proportion of people reporting different degrees of annoyance for a given vibration exposure from railway assessed according to ISO 2631-2:2003 (2003). Curves are shown in their $95 \%$ confidence intervals. $\left(N=752, R_{\text {pseudo }}^{2}=0.01, p<0.001\right.$. $)$

relationships for the railway and construction sources of vibration in the VDV descriptor. It can be clearly seen from these figures that for the same magnitude of vibration exposure, the annoyance response is significantly higher for construction induced vibration than for railway induced vibration. However, it should be noted that differences in the methodology for the estimation of vibration exposure for the two sources may have had an influence on this result.

\section{DISCUSSION AND RECOMMENDATIONS}

\section{A. Robustness and relevance of the exposure-response relationships}

The exposure-response relationships presented in this paper represent the first of their kind for vibration based upon extensive measurement and the first relationships for

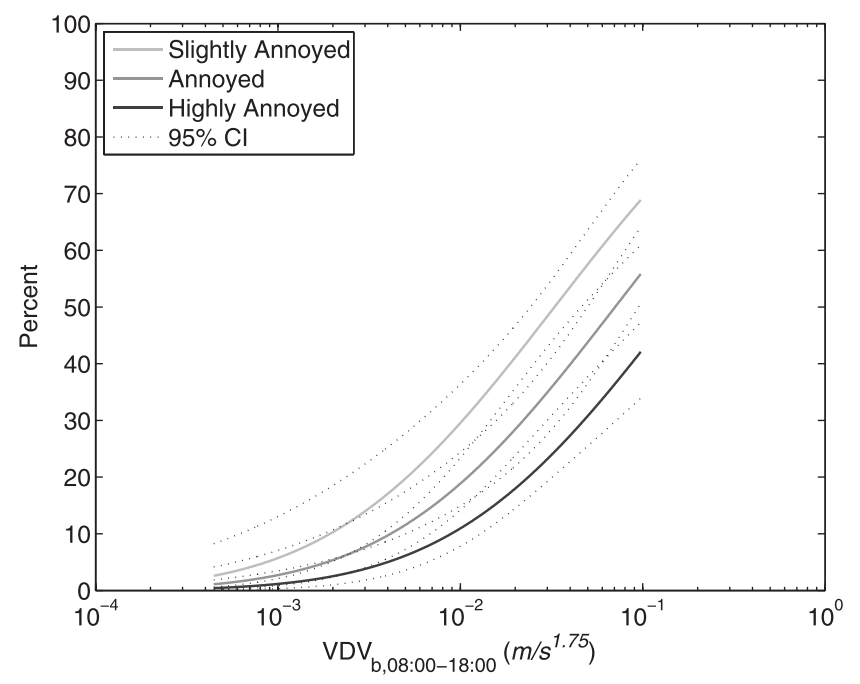

FIG. 9. Exposure-response relationship showing the proportion of people reporting different degrees of annoyance for a given vibration exposure from construction assessed according to BS 6472-1:2008 (2008). Curves are shown in their $95 \%$ confidence intervals. $\left(N=321, R_{\text {pseudo }}^{2}=0.09, p<0.001\right.$. $)$

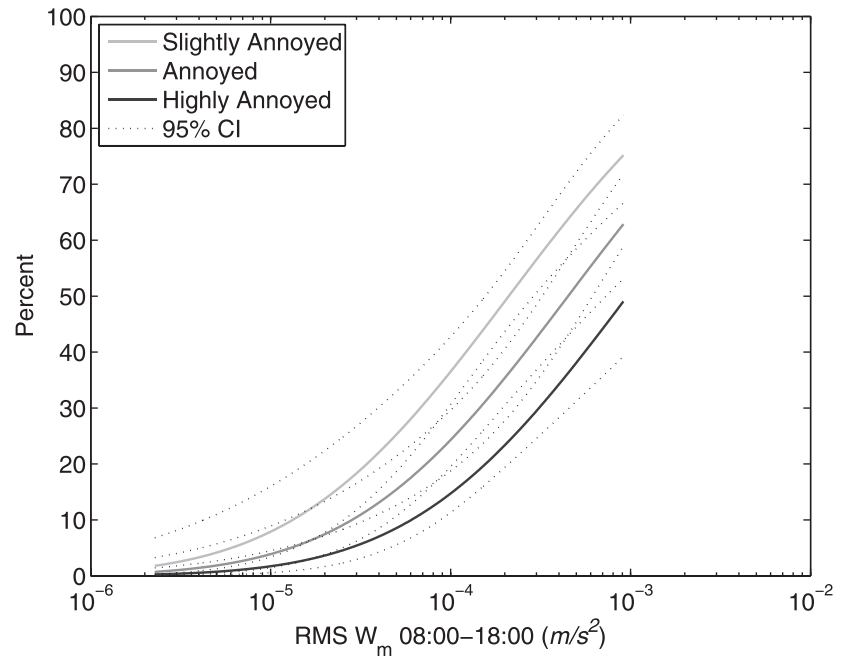

FIG. 10. Exposure-response relationship showing the proportion of people reporting different degrees of annoyance for a given vibration exposure from construction assessed according to ISO 2631-2:2003 (2003). Curves are shown in their $95 \%$ confidence intervals. $\left(N=321, R_{\text {pseudo }}^{2}=0.09, p<0.001\right.$. $)$

construction induced vibration. However, if these relationships are to be used as practical tools for the assessment of the human response to vibration in residential environments, some thought needs to be given as to their validity. In a study by Berry and Flindell (2009), a framework is provided for the assessment of the scientific robustness and relevance with respect to policy of exposure-response relationships for the human response to noise exposure which is reproduced below. In this section, the findings presented in this paper are considered in light of this framework.

(1) The relevance, statistical representativeness, and measurement accuracy of the [exposure], or input variables, measured in the research study are considered in Sec. IV B below.

(2) The relevance, statistical representativeness, and measurement accuracy of the response, or outcome, variables in the research study are considered in Sec. IV B below.

(3) The range of applicability to other types of noise exposure and/or environment not included in the research study is considered in Sec. IV C below.

(4) The range of applicability to other types of adverse health effects not included in the research study is considered in Sec. IV C below.

(5) The statistical strength of the observed [exposure]response relationship in relation to known and/or estimated statistical uncertainty and in relation to the statistical power of the research study as designed is considered in Sec. IV D below.

(6) The relative absence of potential confounding variables that could have been equally or more responsible for the observed [exposure]-response relationships is considered in Sec. IV E below.

(7) The scientific plausibility of the observed [exposure]response relationship considered in terms of known or theoretical biological mechanisms is considered in Sec. IV F below. 


\section{B. Exposure and response variables}

\section{Equivalent energy or cumulative exposure}

The perception of vibration is facilitated through complex physiological mechanisms and is dependent upon, among other factors, the magnitude, frequency, duration, and temporal characteristics of the vibratory stimulus. As it applies to many of the relationships presented in this paper, by expressing vibration exposure as an average or accumulated single figure value over a $24-\mathrm{h}$ period, objective features of vibration exposure salient to perception may not be characterized. As there is no empirical evidence that annoyance due to noise or vibration is accumulated over time, expressing vibration exposure with respect to human response as an equivalent energy or cumulative value somewhat undermines the scientific validity of the relationships presented in this paper. However, as these measures are utilized in national and international standards for the assessment of vibration with regards to human response as well as being the basis for the quantification of vibration limits in a number of nations it is useful from a policy and administrative viewpoint to present these relationships as such.

\section{Appropriateness of descriptor}

The difference between the observed annoyance response between railway and construction induced vibration considering the similar response with regards to absolute perception suggests that further research is needed into the single figure descriptor used as the dependent variable in the relationships. Situational and attitudinal response variables that modify the railway exposure-response relationship presented in this paper have been investigated by Peris et al. (2014).

\section{Exposure and dose}

The single figure vibration descriptors throughout this paper have been expressed in terms of exposure rather than dose and as such the resulting relationships have been referred to throughout as exposure-response rather than the often used dose-response. Exposure and "dose" are often used interchangeably; however, there is an important distinction to be made between these two terms. Vibration dose relates to the total amount of vibration energy absorbed by a subject's body over a given time period whereas vibration exposure relates to the total amount of vibration energy measured at a single point over a given time period. If the subject were to remain in the position at which the vibration was measured over the entire measurement period then the subject's vibration exposure would be equal to their vibration dose. However, this is clearly not the case as people do not remain in a fixed position in their house for 24-h a day. Considering this and also that the measurement methodology was designed to represent the "worst case scenario," it is likely that the vibration exposure used in the calculation of the exposure-response relationships in this paper are an overestimation of each respondent's true vibration dose. However, as it is not the aim of the relationships presented in this paper to predict individual response and when applying the relationships in practice knowledge of the amount of time people in a given population spend in their home will generally not be available, in the case of these relationships vibration exposure is the more appropriate measure.

\section{Applicability to other sources of vibration and adverse effects}

As is the case for environmental noise, it appears from the relationships derived for railway and construction vibration that separate exposure-response relationships may be required for different sources of vibration. Even within the railway, differences in response to vibration exposure from passenger and freight traffic have been demonstrated by Sharp et al. (2014) based on the data analyzed in this paper. Although it may be the case that separate relationships are needed for the two sources, there are a number of factors which may explain the observed differences in the response to the two sources. It may be the case that these differences are partly attributable to inadequacies of currently recommended single figure vibration exposure descriptors to account for salient perceptual features of the vibration exposure. In the field of environmental noise, for example, it has been suggested that psychoacoustic metrics such as loudness and sharpness may be better descriptors of annoyance than engineering metrics such as $L_{\mathrm{Aeq}}$ and $L_{\mathrm{DEN}}$.

An important distinction between the two sources is that railway represents a source of vibration that is a permanent feature of the environment whereas construction represents a source of vibration which is transitory in terms of its presence in the environment. This means that the construction source of vibration induces an abrupt change in the global vibration conditions in the vicinity of the source. There is evidence that for a step change in noise exposure, the increase in annoyance is greater than that which would be predicted by an exposure-response relationship derived under steady state conditions (Brown and Van Kamp, 2009). This may provide a further explanation as to the differences in response to the different sources. This effect is however impossible to investigate using the current dataset and would require a longitudinal survey to be conducted.

Although at present separate relationships are needed to describe the response to the two sources, the use of new physiologically and psychologically relevant descriptors along with knowledge of the response to a change in vibration exposure and the influence of non-exposure factors may allow a unified relationship to be derived for the two sources.

There is currently no evidence that annoyance due to vibration is related to other health effects so the relationships presented in this paper can only be applied for the prediction of annoyance.

\section{Statistical strength}

In field studies into the human response to environmental noise, noise exposure has been found to account for between $4 \%$ and $20 \%$ of the variance in annoyance on the 
individual level (see, for example, Brink and Wunderli, 2010; Fields, 1993; Job, 1988). The Spearman's correlation coefficients between standardized vibration exposure descriptors and annoyance presented shows that the highest correlation for railway induced vibration is 0.16 and 0.42 for construction induced vibration. If these values were to be converted to $R^{2}$ values on the individual level, this would equate to $3 \%$ explained variance for railway induced vibration and $18 \%$ explained variance for construction induced vibration; these values are therefore in line with what might be expected in field studies into the community response to noise. The confidence intervals in the relationships presented in this paper are relatively narrow and are within a range that is comparable with other studies into the human response to vibration (see, for example, Klæboe et al., 2003b; Zapfe et al., 2009) and noise (see, for example, Miedema and Oudshoorn, 2001) from transportation sources. This suggests that, although it appears that there is room for improvement in the exposure-response relationships, the statistical strength of the relationships presented in this paper are in line with what one may expect to achieve from this type of study.

\section{E. Confounding variables}

Careful planning of the survey site selection ensured that there were no sources of environmental vibration other than the source of interest. Of those respondents living in close proximity to a railway, $71.4 \%$ of those interviewed reported noticing vibration from railway activities, $7.5 \%$ from road vehicles, $5.6 \%$ from neighboring homes, and $4 \%$ from airplanes and helicopters. Of those respondents living in close proximity to construction activities, $67.1 \%$ of those interviewed reported noticing vibration from construction sources, $34.3 \%$ from road vehicles, $3.4 \%$ from neighboring homes, and $2 \%$ and $4 \%$ from airplanes and helicopters, respectively.

Vibration is rarely unaccompanied by noise, whether that noise be airborne, groundborne, or vibration induced rattle. There is evidence that both vibration and noise contribute to the annoyance response. Airborne noise had been estimated using the Calculation of Railway Noise procedure in terms of $L_{\mathrm{DEN}}$. Inclusion of the estimated airborne noise exposure as an independent variable in the exposure-response model resulted in a significant parameter estimate for the variable $(z=2.13, p<0.05)$ suggesting that airborne noise exposure has a significant influence on the annoyance response to vibration. There is little research on the human response to groundborne noise and vibration induced rattle. Although it is likely that these modalities of noise exposure contribute to the annoyance response, it is not possible to determine the magnitude of their influence in the current analysis. As each of these modalities is a function of groundborne vibration, their influence will be taken into account in the analysis presented in this paper.

\section{F. Scientific plausibility and causality}

The statistical significance of the exposure-relationships presented in this paper is not necessarily proof of a causal relationship between vibration exposure and annoyance due to vibration. At present, little is known regarding the physiological and psychological mechanisms which result in annoyance due to vibration and as such no definite claim can be made regarding the causality of the observed relationships. However, the findings presented in this paper do suggest that, although not yet fully understood, a relationship does exist between vibration exposure and annoyance in residential environments and that this relationship can be described by curves indicating the proportion of the population expected to express annoyance above a given threshold for a given vibration exposure.

\section{CONCLUSIONS}

Exposure-response relationships have been developed for the human response to railway and construction induced groundborne vibration in residential environments from a large scale socio-vibration survey carried out in the UK. A useful relationship synthesizing railway and construction exposure-responses could not be derived. For a given vibration exposure, construction was found to be more annoying than rail.

The application of frequency weightings defined in BS 6472-1:2008 (2008), BS ISO 2631-1:1997 (1997), and ISO 2631-2:2003 (2003) was found to marginally improve the correlation between vibration exposure and reported annoyance. For the dataset generated by this project, the type of averaging used was largely unimportant with regards to reported annoyance.

The railway used in this research was operating under steady state conditions. It is not possible to investigate a step change in vibration exposure from railway using the current data set, for which a further longitudinal study would be required. This means that the findings from this research cannot be used to predict human response when new railway lines are opened or rail services are altered substantially on existing lines.

\section{ACKNOWLEDGMENTS}

The work was funded by the Department for Environment Food and Rural Affairs. The views and analysis expressed in this report are those of the authors and do not necessarily reflect those of the Department for Environment Food and Rural Affairs. The work was performed at the University of Salford between January 2008 and March 2011. The authors would like to thank all the University of Salford researchers that worked on the project, Mags Adams, Geoff Kerry, Rodolfo Venegas, Andy Elliott, Victoria Henshaw, Phil Brown, Deborah Atkin, Nathan Whittle, George Perkins, Natalia Szczepanczyk, Sharron Henning, Ryan Woolrych, Heather Dawes, Amy Martin, Maria Beatrice Aquino-Petkos, Laura Jane Buckley, Catherine McGee, Andrew Caunce, Valentin Le Bescond, Stephanie Jones, Dawn Smail, Andrew King, Lauren Hunt, Michael Gerard Smith, and Tomos Evans. The work by the University of Salford benefited from guidance by the Defra project steering group. The authors would like to thank the Defra project steering group: Richard Perkins and Colin Grimwood on behalf of Defra, Colin Stanworth 
representing the interests of the British Standards Institution working group for BS6472, Rupert Thornely-Taylor representing the interests of the Association of Noise Consultants, and Henk Miedema, Sabine Janssen, and Henk Vos from TNO (Netherlands Organization for Applied Scientific Research). This project benefited from guidance in the design of the vibration measurement equipment from the suppliers Guralp Ltd. The peer review of the railway questionnaire was performed by Jim Fields, Larry Finegold, Evy Öhrström, Peter Brooker, and Gary J Raw. This research would not have been possible without the kind cooperation of the residents that took part in the field trials.

ANC (2001). Association of Noise Consultants Guidelines: Measurement and Assessment of Groundborne Noise and Vibration (ANC guidelines), Fresco, pp. 1-173.

Arnberg, P. W., Bennerhult, O., and Eberhardt, J. L. (1990). "Sleep disturbances caused by vibrations from heavy road traffic," J. Acoust. Soc. Am. 88, 1486-1493.

Bellmann, M. A. (2002). "Perception of whole-body vibrations: From basic experiments to effects of seat and steering-wheel vibrations on the passenger's comfort inside vehicles," Ph.D. thesis, University of Oldenburg, Germany.

Berry, B. F., and Flindell, I. H. (2009). "Estimating dose-response relationships between noise exposure and human health impacts in the UK," Defra (London).

Brink, M., and Wunderli, J.-M. (2010). "A field study of the exposureannoyance relationship of military shooting noise," J. Acoust. Soc. Am. 127, 2301-2311.

Brown, A., and Van Kamp, I. (2009). "Response to a change in transport noise exposure: A review of evidence of a change effect," J. Acoust. Soc. Am. 125, 3018-3029.

BS 6472-1:2008 (2008). Guide to evaluation of human exposure to vibration in buildings. Vibration sources other than blasting (British Standards Institution, London).

BS 6841:1987 (1987). Guide to measurement and evaluation of human exposure to whole-body mechanical vibration and repeated shock (British Standards Institution, London).

BS EN ISO 8041:2005 (2005). Human response to vibration. Measuring instrumentation (British Standards Institution, London)

Condie, J., Steele, A., Whittle, N., Brown, P., and Waddington, D. (2011). "Human response to vibration in residential environments (NANR209)," Technical Report 2: Measurement of Response, University of Salford, Defra, London.

Fidell, S., Pearsons, K., Silvati, L., and Sneddon, M. (2002). "Relationship between low-frequency aircraft noise and annoyance due to rattle and vibration," J. Acoust. Soc. Am. 111, 1743-1750.

Fidell, S., Silvati, L., and Pearsons, K. (1999). "Field study of the annoyance of low-frequency runway sideline noise," J. Acoust. Soc. Am. 106, $1408-1415$.

Fields, J. M. (1993). "Effect of personal and situational variables on noise annoyance in residential areas," J. Acoust. Soc. Am. 93, 2753-2763.

Fields, J. M., de Jong, R. G., Gjestland, T., Flindell, I. H., Job, R. F. S., Kurra, S., Lercher, P., Vallet, M., Guski, R., Felscher-Suhr, U., and Schuemer, R. (2001). "Standardized general-purpose noise reaction questions for community noise surveys: research and a recommendation," J. Sound Vib. 242, 641-679.

Fields, J. M., and Walker, J. (1982). "The response to railway noise in residential areas in Great Britain,” J. Sound Vib. 85, 177-255.

Gidlöf-Gunnarsson, A., Ögren, M., Jerson, T., and Öhrström, E. (2012). "Railway noise annoyance and the importance of number of trains, ground vibration, and building situational factors," Noise Health, 14, 190-201.

Groothuis-Oudshoorn, C. G., and Miedema, H. (2006). "Multilevel grouped regression for analyzing self-reported health in relation to environmental factors: the model and its application," Biomet. J. 48, 67-82.

Guski, R. (1999). "The concept of noise annoyance: How international experts see it," J. Sound Vib. 223, 513-527.

Howarth, H., and Griffin, M. (1988). "The frequency dependence of subjective reaction to vertical and horizontal whole-body vibration at low magnitudes,” J. Acoust. Soc. Am. 83, 1406-1413.
ISO 2631-1:1997. (1997). Mechanical vibration and shock-Evaluation of human exposure to whole-body vibration-Part 1: General requirements (International Organization for Standardization, Geneva, Switzerland).

ISO 2631-2:2003. (2003). Mechanical vibration and shock-Evaluation of human exposure to whole-body vibration-Part 2: Vibration in buildings $(1 \mathrm{~Hz}$ to $80 \mathrm{~Hz}$ ) (International Organization for Standardization, Geneva, Switzerland).

ISO/TS 15666:2003. (2003). Acoustics. Assessment of noise annoyance by means of social and socio-acoustic surveys (International Organization for Standardization, Geneva, Switzerland).

Job, R. (1988). "Community response to noise: A review of factors influencing the relationship between noise exposure and reaction," J. Acoust. Soc. Am. 83, 991-1001.

Klæboe, R., Öhrström, E., Turunen-Rise, I., Bendtsen, H., and Nykanen, H. (2003a). "Vibration in dwellings from road and rail traffic-Part III: Towards a common methodology for socio-vibrational surveys," Appl. Acoust. 64, 111-120.

Klæboe, R., Turunen-Rise, I., Hårvik, L., and Madshus, C. (2003b). "Vibration in dwellings from road and rail traffic-Part II: Exposure-effect relationships based on ordinal logit and logistic regression models," Appl. Acoust. 64, 89-109.

Miedema, H., and Oudshoorn, C. G. (2001). "Annoyance from transportation noise: Relationships with exposure metrics DNL and DENL and their confidence intervals," Environ. Health Perspect. 109, 409-416.

Miedema, H., and Vos, H. (1998). "Exposure-response relationships for transportation noise," J. Acoust. Soc. Am. 104, 3432-3445.

Miedema, H., and Vos, H. (1999). "Demographic and attitudinal factors that modify annoyance from transportation noise," J. Acoust. Soc. Am. 105, 3336-3344.

Morioka, M., and Griffin, M. J. (2006). "Magnitude-dependence of equivalent comfort contours for fore-and-aft, lateral and vertical handtransmitted vibration," J. Sound Vib. 295, 633-648.

NT ACOU 106 (2001). "Acoustics: Assessment of annoyance caused by vibrations in dwellings from road and rail traffic by means of sociovibrational and social surveys," Nordtest, Finland.

Ögren, M., and Öhrström, E. (2009). "Effects of railway noise and vibrations on sleep-experimental studies within the Swedish research program TVANE," in Proceedings of Euronoise, pp. 1214-1221.

Parsons, K., and Griffin, M. (1988). "Whole-body vibration perception thresholds," J. Sound Vib. 121, 237-258.

Peris, E., Woodcock, J., Sica, G., Sharp, C., Moorhouse, A. T., and Waddington, D. C. (2014). "Effect of situational, attitudinal and demographic factors on railway vibration annoyance in residential areas," J. Acoust. Soc. Am. 135, 194-204.

Schomer, P., Mestre, V., Fidell, S., Berry, B., Gjestland, T., Vallet, M., and Reid, T. (2012). "Role of community tolerance level (CTL) in predicting the prevalence of the annoyance of road and rail noise," J. Acoust. Soc. Am. 131, 2772-2786.

Schomer, P. D., and Neathammer, R. D. (1987). "The role of helicopter noise-induced vibration and rattle in human response," J. Acoust. Soc. Am. 81, 966-976.

Schultz, T. J. (1978). "Synthesis of social surveys on noise annoyance," J. Acoust. Soc. Am. 64, 377-405.

Sharp, C., Woodcock, J., Sica, G., Peris, E., Moorhouse, A. T., and Waddington, D. C. (2014). "Developing exposure-response relationships for annoyance due to freight and passenger railway vibration exposure in residential environments," J. Acoust. Soc. Am. 135, 205-212.

Sica, G., Peris, E., Woodcock, J. S., Moorhouse, A. T., and Waddington, D. C. (2013). "Design of measurement methodology for the evaluation of human exposure to vibration in residential environments," Sci. Total Environ. (in press).

TRL, Temple, ISVR, and Arup Acoustics (2007). NANR172 Human response to vibration in residential environments, Defra, London.

Woodruff, H. J., and Griffin, M. J. (1987). "A survey of the effect of railway-induced building vibration on the community," Institute of Sound and Vibration Research Technical Report, UK.

Woods, R. (1997). "Dynamic effects of pile installations on adjacent structures," NCHRP 253, National Academy Press, Washington, DC (Transportation Research Board), pp. 8-9.

Zapfe, J. A., Saurenman, H., and Fidell, S. (2009). "Ground-borne noise and vibration in buildings caused by rail transit," TCRP Project D-12. 